\title{
Morphological Features of the Acupuncture Points of Bladder Meridian in the Giant Anteater (Myrmecophaga tridactyla)
}

\author{
Gustavo de Calasans Marques' \& Bruno Cesar Schimming ${ }^{1,2}$
}

\begin{abstract}
Background: The acupuncture points are considered a point in the skin of sensitivity to stimulation. The acupuncture meridians represent the communication between acupuncture points and internal organs. The giant anteater (Mirmecophaga tridactyla) is routinely attended in veterinary centers, and is pivotal to know its morphology and therapies such as acupuncture that, probably, can be used in medical practice. Thus, the aim of this study was to evaluate the morphological substrate in regions that correspond to the transposition of acupuncture points of the Bladder Meridian using radiography, ultrasonography, electrical impedance and histology in the giant anteater.

Materials, Methods \& Results: Seven giant anteaters (six males and one female) were used. The animals were from the Center of Medicine and Research in Wild Animals (CEMPAS), School of Veterinary Medicine and Animal Science, UNESP, Botucatu, São Paulo. The acupoints of Bladder Meridian evaluated were Bladder 11 (B-11), Bladder 18 (B-18), Bladder 23 (B-23), Bladder 25 (B-25), and Bladder 28 (B-28). The locations of the acupoints were transposed based on the location of these acupuncture points in dogs. Four animals were live and were used for radiographic, ultrasonographic, and electrical impedance analysis. Three animals were died and the fragments of this acupoints were destined to histological routine with hematoxylin and eosin (HE) and Masson's Trichrome stains. The giant anteaters studied had fifteen thoracic vertebrae, three lumbar vertebrae, and five sacral vertebrae fused in a single bone. The acupuncture points were characterized by presence of abundant connective tissue at the superficial and intermuscular level, muscular fascia, and many neurovascular bundles in the dermal layer. These bundles consisted of nerves, arteries and veins of various calibers. The spaces between the nerves and blood vessels were filled by loose connective tissue containing adipose cells, capillaries, and sweat glands. Discussion: The network of acupuncture points can be seen as a representation of a network formed by interstitial connective tissue. This hypothesis is supported by ultrasound imaging that demonstrated plans for cleavage of connective tissue at acupuncture points in normal humans. It seems that the anatomical relationship of acupoints and meridians with connective tissue planes is relevant to the mechanism of action of acupuncture and suggests an important integrative role for interstitial connective tissue. The presence of connective tissue was observed in the transposition areas studied in the giant anteater using ultrasound. The main histological structures found in the transposition regions of the acupoints in the giant anteater were the nerve and connective tissue, similar to other studies, who claimed that the nerve is the main histological component of an acupoint. Therefore, there are reports suggesting that the network of acupoints and meridians can be seen as a representation of a network formed by interstitial connective tissue and that this relationship is important for the therapeutic mechanism of acupuncture. Based on the results of this study, it is possible to infer that the studied regions present a morphological substrate that is consistent with the characteristics of an acupuncture point. Thus, it is suggested that there are probably acupuncture points in these regions in the giant anteater, which makes possible the use of this alternative medical therapy for the treatment of these animals.
\end{abstract}

Keywords: xenarthra, wild animals, tradicional Chinese medicine, acupuncture. 


\section{INTRODUCTION}

The acupuncture points or acupoints are considered a point in the skin of sensitivity to stimulation and reduced electrical resistance and is an area of electrical conductivity intensely increased when compared with surrounding skin areas. These are located near the tendon joints and sheaths, vessels, nerves and intramuscular septa, at the musculotendinous junction, at the sites of greater diameter of the muscle and in the regions of penetration of the nerve bundles in the skin $[9,16,22]$.

Acupuncture meridians constitute channels connecting the surface of the body with internal organs. Specific points on the back, parallel to the midline of the spine, belong to the Bladder Meridian that is located on the dorsal side $1.5 \mathrm{~cm}$ lateral to the midline. Each of these acupoints refers to an internal organ that is organized approximately in the same vertical plane as its related point [20].

The giant anteaters (Myrmecophaga tridactyla) are mammals that are present throughout Brazilian territory [14]. The main causes of decline in wildlife populations are the deterioration and reduction of habitats, hunting, road crashes and forest fire [13]. The giant anteater became more and more an animal attended in veterinary centers because of the causes cited previously [17]. Thus, this study aimed to analyze the morphological substrate of acupoints selected from the Bladder Meridian by means of histological, ultrasonographic, radiographic and of electrical impedance studies, to contribute to the medical practice and with the possibility of using the acupuncture therapy in this animal species.

\section{MATERIALS AND METHODS}

\section{Animals}

Seven giant anteaters (Myrmecophaga tridactyla) (six males and one female) were used. The animals were from the Center of Medicine and Research in Wild Animals (CEMPAS), School of Veterinary Medicine and Animal Science, UNESP, Botucatu. The age was estimated, being six adults and one of approximately four months of life. The causes of death were not related to the present study. Four live animals were used for radiography, ultrasonography and electrical impedance. Three dead animals were used to histological routine.

\section{Transpositional acupoints}

The acupoints evaluated in this study were Bladder 11 (B-11), Bladder 18 (B-18), Bladder 23 (B-23), Bladder 25 (B-25) and Bladder 28 (B-28). The locations of the acupoints were transposed based on the location of these acupuncture points in dogs [24]. Thus, the studies were performed in the regions of the Bladder Meridian of the giant anteater which corresponds to the selected acupoints in dogs. The cun is a proportional or relative unit of measurement used to guide the relative placement of acupuncture points. One cun is equivalent to the length of the first caudal vertebra $(\mathrm{Cd} 1)$ or the width of the last rib [24]. In the dog, the acupoint B-11 (cervicothoracic region) is located at the cranial margin of the scapula, 1.5 cun lateral to the spinal process of the first thoracic vertebra (T1); B-18 (thoracic region) is located on the dorsolateral surface of the spine, 1.5 cun lateral to the caudal margin of the spinal process of the tenth thoracic vertebra; B-23 (region between the second (L2) and third (L3) lumbar vertebrae), is located on the dorsolateral surface of the spine, 1.5 cun lateral to the caudal margin of the spinous process of L2; B-25 (lumbar region) is located on the dorsolateral surface of the spine, 1.5 cun lateral to the caudal margin of the spinal process of the fifth lumbar vertebra; and B-28 (sacral region) is located in the first sacral intervertebral space (between the first and second sacral vertebrae), 1.5 cun lateral to the mediodorsal line, between the sacrum and the medial border of the wing of ilium [24].

\section{Image and electrical impedance analysis}

The live animals were submitted to radiographic and ultrasound examinations in the Diagnostic Imaging Service, and to electrical impedance in the Acupuncture Service, School of Veterinary Medicine and Animal Science, UNESP. A combination of 10 $\mathrm{mg} / \mathrm{kg}$ of ketamine hydrochloride ${ }^{1}$ and $0.4 \mathrm{mg} / \mathrm{kg}$ of midazolam maleate ${ }^{2}$ was applied intramuscularly for chemical immobilization of the animals.

\section{Radiographic analysis}

For the acquisition of radiographic images of the vertebral column, the lateral and ventrodorsal incidences were performed with standard techniques, with $100 \mathrm{~cm}$ film focus distance, in a digital X-ray DR-F ${ }^{3}$. The protocol of the radiographic technique ranged from $65-75 \mathrm{kVp}$ and $8 \mathrm{mAs}$ to the spine. After acquisition, the radiographic images were stored in a PACS medical imaging system ${ }^{4}$. 


\section{Ultrasonographic analysis}

The ultrasound was performed using a ultrasound system $\left(\text { MyLab }{ }^{\mathrm{TM}} 40 \mathrm{VET}\right)^{5}$ with a linear multifrequency transducer $(8-13 \mathrm{MHz})$. The intercostal paravertebral spaces from the articulation of the seventh cervical vertebra with the first thoracic to the last sacral vertebra were evaluated.

\section{Electrical impedance analysis}

The electrical impedance was performed in live animals since the acupoints can be located by anatomical manipulation and by electrical resistance. In order to do so, we used the Cosmotron RRD System TE $99^{6}$ impedance device with the intensity variation of 10 to $300 \mathrm{~Hz}$, along the intercostal spaces of the thoracic, lumbar and sacral vertebrae, in parallel segments of six animals. The evaluated points were determined by anatomical comparison with domestic species, measurement of the proportions of the individuals themselves, ultrasonographic examination and palpation. The region evaluated was located in the caudal aspect of the transverse process of the thoracic and lumbar vertebrae, approximately $3 \mathrm{~cm}$ lateral to the midline of the vertebral column. In turn, in the sacrum, the points were located on the sacral foramina.

\section{Histological analysis}

For the histological analysis, cervicothoracic, thoracic, thoracolumbar and lumbosacral fragments were collected from the intercostal paravertebral region, caudal to the transverse process of the vertebrae. The sites of collection corresponded to the regions of the Bladder Meridian in dog: the cervico-thoracic region corresponding to acupoint Bladder 11; thoracic region corresponding to Bladder 18; region between the second and third lumbar vertebrae corresponding to Bladder 23; lumbar region corresponding to Bladder 25; and sacral region corresponding to Bladder 28 [17]. The collected material was fixed in $4 \%$ paraformaldehyde for $24 \mathrm{~h}$ and submitted to routine inclusion for Paraplast $^{\mathrm{TM}-7}$. Following the inclusion, a microtomy was performed to obtain $5 \mu \mathrm{m}$ thick histological sections, mounted on silanized slides and stained with hematoxylin and eosin (HE) and Masson's Trichrome.

\section{RESULTS}

\section{Radiographic analysis}

Radiographic analysis was performed with the objective of standardizing the number of thoracic and lumbar vertebrae found in the vertebral column of the anteater. The ventrodorsal and lateral incidences allowed to observe the vertebral column in all its extension. All the animals studied presented 15 thoracic vertebrae (T1-T15), 3 lumbar vertebrae (L1-L3) and 5 sacral vertebrae (S1-S5). In adult animals, the thoracic and lumbar vertebrae were individualized, while the sacral vertebrae were fused to form a single bone, the sacrum. The thoracic and lumbar vertebrae were easily differentiated by the rectangular vertebral body, separated by radiolucent intervertebral spaces. Intervertebral foramina were observed in all segments of the spine. The xenarthro processes were noted along the intervertebral foramina (Figure 1).

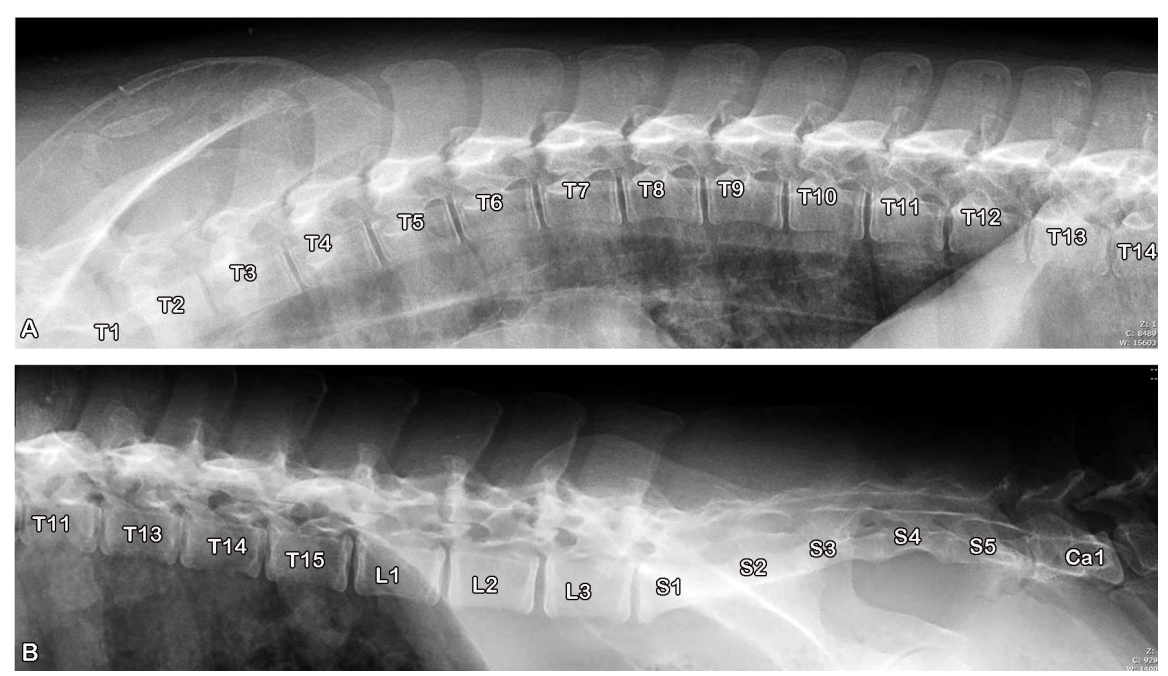

Figure 1. Lateral radiograph of the vertebral column in the giant anteater (Myrmecophaga tridactyla). In (A), thoracic vertebrae (T1-T14) and (B) thoracic vertebrae (T11-15), lumbar vertebrae (L1-L3), sacral vertebrae (S1-S5) and first caudal vertebra (Ca1). 


\section{Ultrasound analysis}

The ultrasound evaluation showed that the main component found in the acupoints studied was the connective tissue, which appeared in the form of fascial sheets, ligaments and tendionous structures (Figure 2). Here, it were observed thicker images composed of thin, hyperechogenic, parallel lines, without posterior acoustic shadow formation, which allows to infer that they are more dense conjunctive structures such as intramuscular fascial sheets (Figure 2 B \& D). Dorsally to the dorsal arches of the vertebral bodies, an elongated, hypoechogenic, homogeneous image with parallel dorsal and ventral lines could be visualized, defining its limits. This image was located immediately dorsal to the vertebral bone surface and was hypoechoic and more homogenous in relation to the connective tissue of the muscular fascia and tendons, suggesting that they may be ligament structures (Figure 2 A, C \& D). It was also possible to note the bone surfaces of the vertebral bodies, transverse and lateral processes and the costal arch in the thoracic vertebrae, which were regular and of smooth articular surfaces (Figure 2).

\section{Electrical impedance assessment}

All points were compared to random points, not correlated to any meridian, always with the same intensity of current per point. The test showed lower electrical resistance in the "true" regions, being positive for the analysis, compared to "false" random points. The thoracic region required a greater intensity in the electrical current, which demonstrates a greater electrical resistance at these points (can be explained by the low amount of connective tissue in these areas, as demonstrated by ultrasound). The lumbar region demonstrated greater sensitivity to the test, demonstrating lower electrical resistance compared to the thoracic and lumbar.

\section{Histological analysis}

Microscopic analysis revealed that the skin of the giant anteater (Myrmecophaga tridactyla) is formed by the epidermis and dermis. It was possible to observe the various stratum of the epidermal layer of the skin: corneum, lucidum, granulosum, spinosum and basale (Figure 3). The regions of acupoints investigated in the giant anteater showed a specific organization of connective tissue. Many neurovascular bundles appeared in the dermal layer, close to the epidermis. These bundles were composed of nerves, arteries and veins of various calibers. The spaces between the nerves and vessels were filled by loose connective tissue, in which adipose cells were observed (Figure 4). These neurovascular bundles also appeared along the merocrine type sweat glands (Figure 4 A \& C).

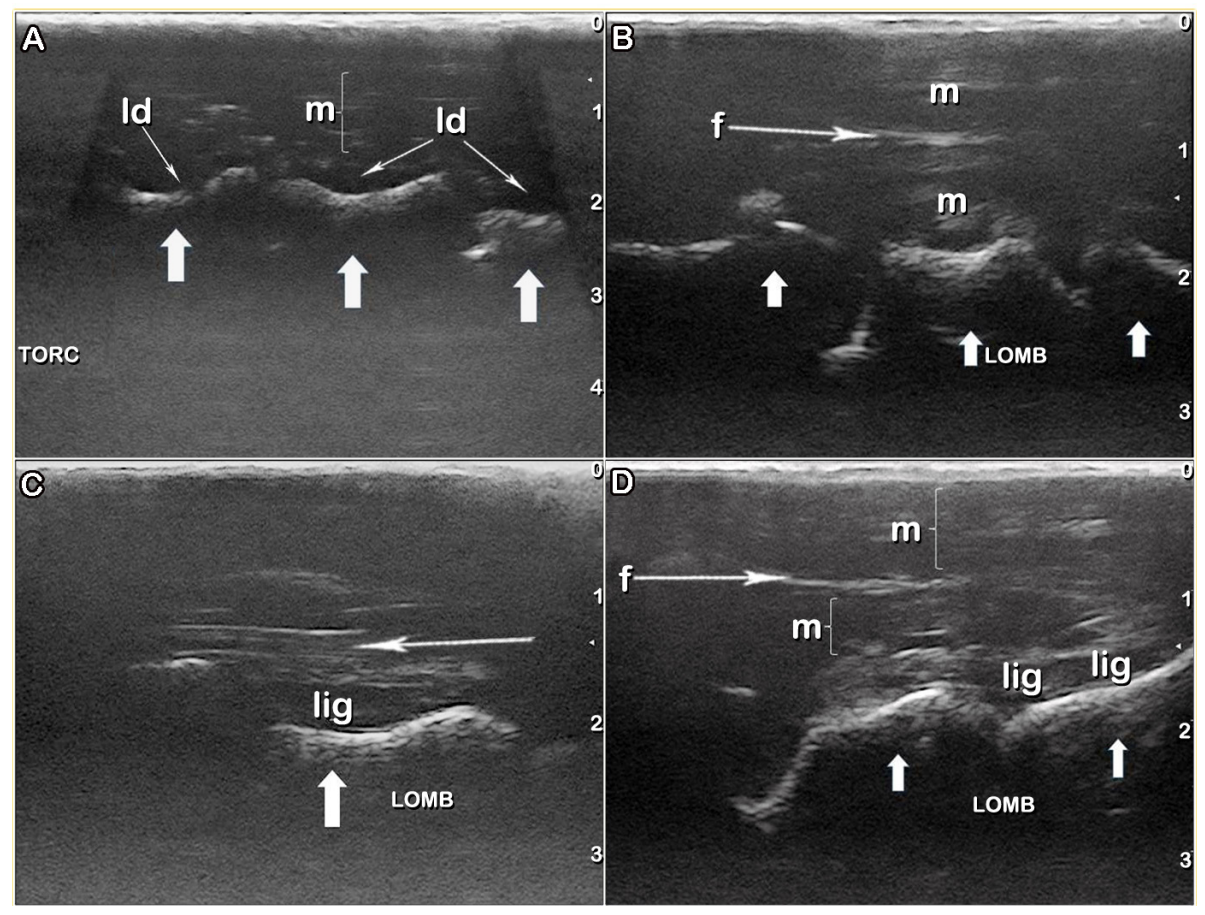

Figure 2. Ultrasound images of the thoracic (A), thoracolumbar (B), and lumbar (C and D) regions in the giant anteater. Note the connective tissue in the form of muscular fascia (f) between the muscular groups (m), the connective tissue forming the dorsal thoracic ligament (ld) ventrally to the vertebral bone surface (thick arrows). The connective tissue also appeared in the form of ligament (lig) and ligament structures (thin arrows). 


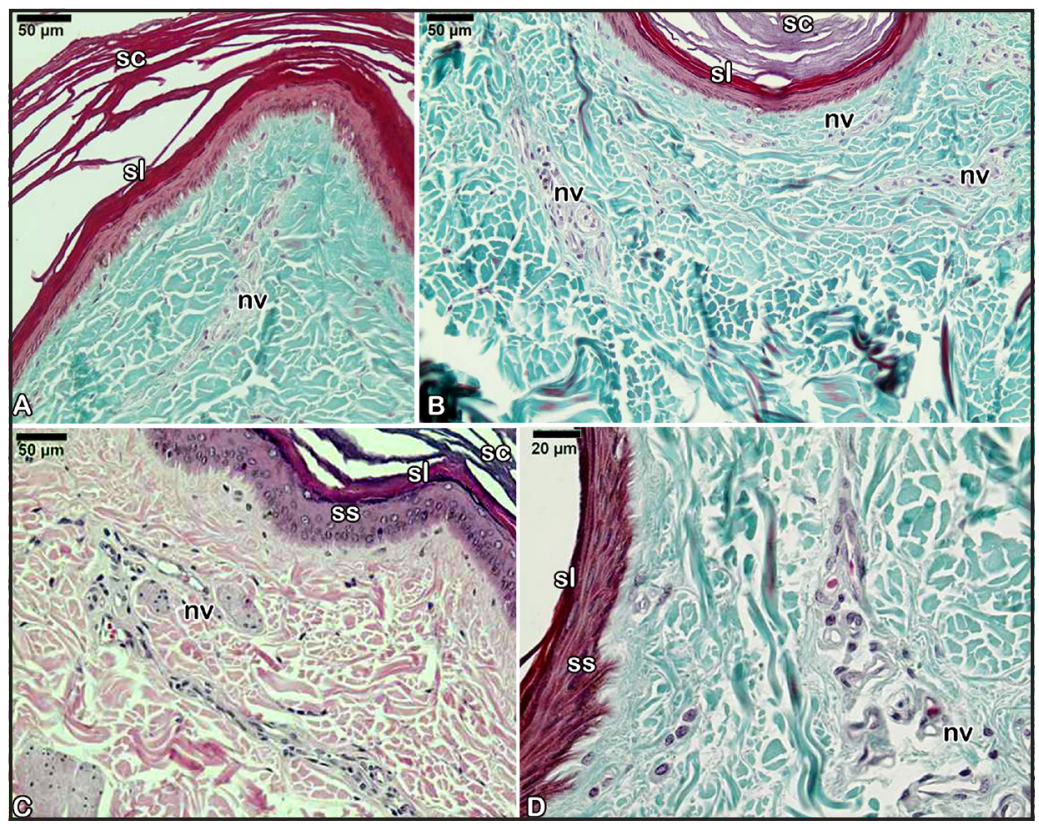

Figure 3. Regions of acupuncture points B-11 (A), B-18 (B), B-23 (C) and B-28 (D) in the giant anteater. Note the corneum (sc), lucidum (sl), spinosum (ss) stratum of the epidermis, and neurovascular bundles (nv) found in the dermis [Masson's trichrome].

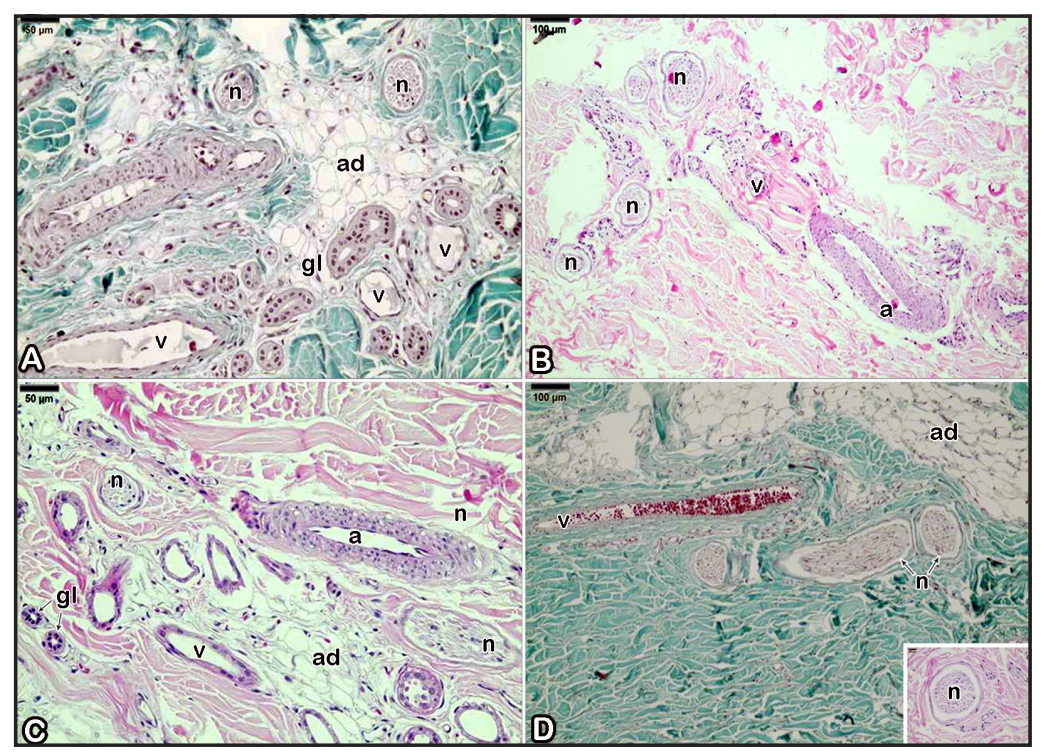

Figure 4. Regions of the acupuncture points B-11 (A), B-18 (B), B-23 (C) and B-25 (D) in the giant anteater. Neurovascular bundles consisting of nerves (n), veins (v) and arteries (a). Note also the adipose tissue (ad) and sweat glands (gl) that appear in the loose connective tissue [Masson's trichrome (A, D); Hematoxylin and Eosin (B, C and Inset)].

\section{DISCUSSION}

In this study, the morphological substrate of acupuncture points in giant anteater (Myrmecophaga tridactyla) was evaluated by means of histological, ultrasonography, digital radiography, and electrical impedance analyzes. Anatomical studies on giant anteaters are scarce. The thoracolumbar vertebrae of the three species of the family Myrmecophagidae were described [6]. The analysis showed that giant anteater may have 15 or 16 thoracic vertebrae and two or three lumbar vertebrae. Later studies demonstrated a constancy in the number of lumbar vertebrae, always being three vertebrae in the studied animals [2,3]. In this study, according to the radiographs performed, all the animals presented 15 thoracic vertebrae and three lumbar vertebrae, which is in agreement with the literature already described and may even suggest an invariable number of vertebrae, being the variation 
of a thoracic vertebra or lumbar vertebra, a possible transitional vertebra.

The mechanisms of action of acupuncture have not been fully revealed and remain challenging. During placement of acupuncture points, the tissue grap sensation or the de qi occurs and it is felt by both the patient and the acupuncturist, in which there is increase of resistance to movement and a formation of a connective whorl with the needle rotation and this may initiate the acupuncture response [7]. This sensation has been described for more than 2,000 years and is still considered essential in acupuncture $[11,20]$. This resistance occurs due to the interaction of the connective tissue and other surrounding tissues during manipulation of the needle resulting in a folding of elastic fibers and collagen that "screw and tighten" the needle. This manipulation transmits a mechanical signal to connective tissue cells via mechanotransduction, propagating the signal through adjacent tissues $[7,10,11,15,20]$.

Studies have shown that acupuncture points present a different biomechanical response to needling compared to non-acupuncture points and that this biomechanical response may involve connective tissue and that the network formed by acupuncture meridians may correspond to a network formed by connective tissue. Although the physiological significance of this association is unclear at present, some researchers have suggested that collagen content in connective tissue transmits electrical conductive properties and that connective tissue can act as the medium through which electrical communications moves within the meridian network [1].

Ultrasound examinations performed in the transposition regions of the acupoints in the giant anteater showed abundant connective tissue at the superficial and intermuscular level, fine muscle fibers, fascia and distinct muscle groups. Thus, it is clear that the stimulation of this region will be directly related to these tissues. It has been reported that during stimulation of muscle fibers there are sensations of weight, distension and pain typically associated with $d e$ qi. It seems that the sensation perceived during the de qi is due to a muscular contraction $[11,12,20]$. The de qi sensation is essential for the therapeutic effect of acupuncture, and it is not due to muscle contraction but to the involvement of connective tissue. During the rotation of the acupuncture needle, the connective tissue near the needle creates a mechanical coupling between needle and tissue $[11,12,20]$. Thus, manipulation of the needle would create cellular changes that would propagate along the planes of connective tissue and could even alter the extracellular matrix. Changes in matrix composition in response to this coupling, which would act as mechanical stress and could be an important form of communication between different cell types [21].

There are reports suggesting that the network of acupoints and meridians can be seen as a representation of a network formed by interstitial connective tissue and that this relationship is important for the therapeutic mechanism of acupuncture [12]. Acupuncture meridians are believed to form a network along the body, connecting peripheral tissues between themselves and with central viscera [20]. The interstitial connective tissue, which includes the subcutaneous tissue, constitutes a continuous network that involves the muscles of limbs, bones and tendons and extends to connective tissue planes of the thoracic and pelvic girdle, thoracic and abdominal walls, head and neck [12]. In addition, this network of connective tissue is continuous with more specialized connective tissues such as periosteum, perimysium, pericardium, pleura, peritoneum and meninges. This connective tissue network is important for the therapeutic mechanism of acupuncture [10]. In the ultrasonographic evaluation carried out in the regions studied in the giant anteater, an abundance of connective tissue was observed in the form of muscular fascias, ligament and tendinous structures, which allows to infer that connective tissue, in the most diverse forms, really is an important structure and is present in the acupuncture points in the giant anteater.

The regions of transposition of the acupoints in the giant anteater had a morphology characterized by several stratum of the epidermal layer of the skin, connective tissue, many neurovascular bundles in the dermal layer, consisting of nerves, arteries and veins of various calibers, loose connective tissue between the nerves and vessels, adipose cells and sweat glands. Thus, it is believed that the deformation of the connective tissue matrix is not restricted to the needle area, but would spread along the interstitial planes of the connective tissue, dermis, subcutaneous, vessels, nerves, muscle tissue and their various receptors, generating a wave of sensory activation with intra and extracellular changes. This subsequent transduction may explain the local and systemic therapeutic effects of acupuncture as well as its prolonged action [11].

The impedance or resistance of the acupuncture points can be used for clinical evaluation of the patient, since a physiological and pathological alteration of the organs reflects a variation of the electrical resistance in the corresponding points and meridians [8]. There are studies in humans that demonstrate that the meridians 
showed lower electrical resistance in patients with severe diseases of the immune system and injury of spinal cord in relation to healthy people [25]. The impedance tests of this study were performed on the Bladder Meridian based on the theory described for domestic animals $[17,24]$ and compared to random points not correlated to any meridian. The test demonstrated the greater conduction of the caudal regions of the transverse processes of the thoracic and lumbar vertebrae, approximately $3 \mathrm{~cm}$ lateral to the midline of the spine and in the sacrum, in the regions located on the sacral foramina, that is, lower electrical resistance of the acupoints belonging to this meridian.

The anatomical nature of the acupuncture points represents a neural and vascular bundle, with numerous free nerve endings, artery, vein, lymphatic channel and several mast cells [23]. Most acupuncture points in animals also represent regions of skin with low electrical resistance and high electrical conductivity. Once stimulated the acupoint, the nerve impulse propagates in ascendancy via sensory nerves until reaching the spinal cord. Most nerve fibers include the pathways of pain, although the acupuncture stimulus also involves proprioceptive fibers [24]. Based on the previously reported and the description of the brachial and lumbosacral plexus in anteater $[3,18]$, we can infer that the impulses from the stimulation in the regions analyzed in this study, would propagate through the nerves originating from the brachial and lumbosacral plexuses. Thus, B-11 would be related to the radial nerve $(\mathrm{C} 5, \mathrm{C} 6, \mathrm{C} 7, \mathrm{C} 8$ and $\mathrm{T} 1)$, median nerve (C5, C6, C7, C8 and T1), ulnar nerve (C5, $\mathrm{C} 6, \mathrm{C} 7, \mathrm{C} 8$ and $\mathrm{T} 1)$ and lateral thoracic nerve (C7, C8 and T1); B-18 to the intercostal nerve; B-23 to genitofemoral nerve (T15, L1, L2), lateral cutaneous femoral nerve (T15, L1 and L2), femoral nerve (T16, L1 and L2) and obturator nerve (L1, L2 and L3); B-25 to the obturator nerve (L1, L2 and L3); B-28 to obturador nerve (L1,LS1 and L3), cranial gluteal nerve (L2, S1 and S2), caudal gluteal nerve (L2, S1, S2 and S3), ischiatic nerve (L3, S1, S2 and S3), and pudendal nerve (S4 and S5).

The transposition regions studied in the giant anteater are composed of several neurovascular bundles found in the dermis, inserted in the connective tissue. There seems to be a consensus in the literature on the morphology found in an acupoint. In the acupoint sites, there are free nerve endings (and other types of receptors) and nerve fibers involved in a connective tissue sheath or vascular wall, which may be the essential component that triggers sensations and the therapeutic effects of acupuncture [5]. The main histological structures found in the transposition regions of the acupoints in the giant anteater were the nerve and connective tissue, similar to other studies, who claimed that the nerve is the main histological component of an acupoint $[15,19]$.

\section{CONCLUSIONS}

Based on the results of this study, it is possible to show that the regions studied in the giant anteater have a morphological substrate compatible with the characteristics of an acupoint, for example, these regions show a typical pattern of construction with several neurovascular bundles located in the dermis, in the connective tissue. These bundles are formed by nerves, arteries and veins, surrounded by connective tissue. It appears that neurovascular bundles could function as a morphological substrate and a form of information transfer to and from acupuncture points [4]. Thus, it is suggested that probably the regions studied in the giant anteater may correspond to acupoints B-11, B-18, B-23, B-25 and B-28 transposed from that reported for the dog. In this way, it is feasible to use acupuncture in the clinical routine in these animals, using acupuncture techniques such as gold implant, ozonotherapy and others. These data represent the first in veterinary medicine on the acupuncture points in the giant anteater and serve as a baseline for continued study. Additional studies should also investigate the clinical evidence of this alternative veterinary medical therapy.

\section{MANUFACTURERS}

${ }^{1}$ König Brasil Ltda. São Paulo, SP, Brazil.

${ }^{2}$ Roche Brasil S/A. Jaraquá, RJ, Brazil.

${ }^{3}$ GE Healthcare. São Paulo, SP, Brazil.

${ }^{4}$ Synapse Fuji Medical System. Tokyo, Japan.

${ }^{5}$ ESAOTE Benelux B.V. Maastricht, The Netherlands.

${ }^{6}$ Cosmotron. São Paulo, SP, Brazil.

${ }^{7}$ Sigma. Saint Louis, MO, USA.

Acknowledgments. The authors would like to thanks Center of Medicine and Research in Wild Animals (CEMPAS) for providing the animals. This study was financed in part by the Coordenação de Aperfeiçoamento de Pessoal de Nível Superior - Brasil (CAPES) - Finance Code 001.

Ethical approval. All procedures, treatments and animal care were in compliance with the Institutional Ethics Committee on the Use of Animals of the School of Veterinary Medicine and Animal Science, UNESP (CEUA 159/2016).

Declaration of interest. The authors report no conflicts of interest. The authors alone are responsible for the content and writing of the paper. 


\section{REFERENCES}

1 Ahn A.C., Wu J., Badger G.J., Hammerschlag R. \& Langevin H.M. 2005. Electrical impedance along connective tissue planes associated with acupuncture meridians. BMC Complementary and Alternative Medicine. 5: 10. doi. org/10.1186/1472-6882-5-10

2 Babicsak V.R., Doiche D.P., Mamprim M.J., Vulcano L.C., Zardo K.M., Santos D.R.D. \& Teixeira C.R. 2012. Mielotomografia e reconstrução tridimensional em Myrmecophaga tridactyla: compressão medular por fratura compressiva vertebral - Relato de caso. Revista de Educação Continuada em Medicina Veterinária e Zooteccnia CRMV-SP. 10: 44-45.

3 Cruz V.S., Cardoso J.R., Araújo L.B.M., Souza P.R., Borges N.C. \& Araújo E.G. 2014. Aspectos anatômicos do plexo lombossacral de Myrmecophaga tridactyla (Linnaeus, 1758). Biosciences Journal. 30: 235-244.

4 Egerbacher M. 2006. Anatomia e histologia de pontos de acupuntura selecionados de bovinos e caninos. In: Schoen A.M. (Ed). Acupuntura Veterinária. Da Arte Antiga à Medicina Moderna. 2.ed. São Paulo: Roca, pp.21-23.

5 Hwang Y.C. \& Egerbacher M. 2006. Anatomia e classificação dos acupontos. In: Schoen A.M. (Ed). Acupuntura Veterinária. Da Arte Antiga à Medicina Moderna. 2.ed. São Paulo: Roca, pp.17-23.

6 Jenkins J.R. 1970. Anatomy and function of expanded ribs in certain edentates and primates. Journal of Mammalogy. 51: 288-301. doi.org/10.2307/1378479

7 Jeune S., Henneman K. \& May K. 2016. Acupuncture and equine rehabilitation. Veterinary Clinics: Equine Practice. 32: 73-85. doi.org/10.1016/j.cveq.2015.12.004

8 Jones D.M., Smallwood R.H., Hose D.R., Brown B.H. \& Walker D.C. 2003. Modelling of epithelial tissue impedance measured using three different designs of probe. Physiological Measurement. 24: 605-623. doi.org/10.1088/0967$3334 / 24 / 2 / 369$

9 Koski M.A. 2011. Acupuncture for zoological companion animals. Veterinary Clinics: Exotic Animal Practice. 14: 141-154. doi.org/10.1016/j.cvex.2010.09.010

10 Langevin H.M. \& Yandow J.A. 2002. Relationship of acupuncture points and meridians to connective tissue planes. Anatomical Record. 269: 257-265. doi.org/10.1002/ar.10185

11 Langevin H.M., Churchill D.L. \& Cipolla M.J. 2001. Mechanical signaling through connective tissue: a mechanism for the therapeutic effect of acupuncture. FASEB Journal. 15: 2275-2282. doi.org/10.1096/fj.01-0015hyp

12 Langevin H.M., Churchill D.L., Wu J., Badger G.J., Yandow J.A., Fox J.R. \& Krag M.H. 2002. Evidence of connective tissue involvement in acupuncture. FASEB Journal. 16: 872-874. doi.org/10.1096/fj.01-0925fje

13 Macedo L.S.M., Azevedo R.B. \& Pinto F. 2010. Área de vida, uso do habitat e padrão de atividade do tamanduábandeira na savana de Boa Vista, Roraima. In: Barbosa R.I. \& Melo V.F. (Eds). Roraima: Homem, Ambiente e Ecologia. Boa Vista: FEMACT, pp.585-602.

14 Miranda F. 2006. Cingulata (Tatus) e Pilosa (Preguiças e Tamanduás). In: Cubas Z.S., Silva J.C.R. \& Catão-Dias J.L. (Eds). Tratado de Animais Selvagens. 2.ed. São Paulo: Roca, pp.710-721.

15 Pomeranz B. 1998. Scientific basis of acupuncture. In: Stux G. \& Pomeranz B. (Eds). Basis of Acupuncture. 4th edn. Berlin: Springer, pp.6-47.

16 Roasted P. 1998. The use of acupuncture in dentistry: a review of the scientific validity of published papers. Oral diseases. 4: 100-104. doi.org/10.1111/j.1601-0825.1998.tb00265x

17 Schoen A.M. 2006. Acupuntura Veterinária. Da Arte Antiga à Medicina Moderna. São Paulo: Roca, pp.15-80.

18 Souza P.R., Cardoso J.R., Araújo L.B.M., Moreira P.C., Cruz V.S. \& Araújo E.G. 2014. Gross anatomy of the brachial plexus in the giant anteater (Myrmecophaga tridactyla). Anatomia Histolologia Embryologia. 43: 341-345. doi.org/10.1111/ahe.12080

19 Steiss J.E. 2006. Base neurofisiológica da acupuntura. In: Schoen A.M. (Ed). Acupuntura Veterinária. 2.ed. São Paulo: Roca, p.24.

20 Stux G., Berman B. \& Pomeranz B. 2012. Basics of Acupuncture. Berlin: Springer-Verlag. pp.7-55.

21 Swartz M.A., Tschumperlin D.J., Kamm R.D. \& Drazen J.M. 2001. Mechanical stress is communicated between diferente cell types to elicit matrix remodeling. Proceedings of National Academy of Sciences USA. 98: 6180-6185. doi.org/10.1073/pnas.111133298

22 Taffarel M.O. \& Freitas P.M.C. 2009. Acupuntura e analgesia: aplicações clínicas e principais acupontos. Ciência Rural. 39: 2665-2672. 
G.C. Marques \& B.C. Schimming. 2020. Morphological Features of the Acupuncture Points of Bladder Meridian in the Giant Anteater (Myrmecophaga tridactyla).

23 Urano K. \& Ogasawara S. 1978. A fundamental study on acupuncture point phenomena of dog body. Kitasato Archives of Experimental Medicine. 51: 95-109.

24 Xie H. \& Preast V. 2011. Os 12 canais regulars. In: Xie H. \& Preast V. (Eds). Acupuntura Veterinária Xie. São Paulo: MedVet, pp.5-13.

25 Yiyun Z. 2008. Avaliação das impedâncias em pontos de acupuntura. 39f. Botucatu, SP. Trabalho de conclusão de curso. Universidade Estadual Paulista UNESP. 